\title{
Adsorption of hexavalent chromium by graphite-chitosan binary composite
}

\author{
RAJENDRA S DONGRE \\ Department of Chemistry, RTM Nagpur University, Nagpur 440033, India
}

MS received 28 February 2015; accepted 18 December 2015

\begin{abstract}
Graphite chitosan binary (GCB) composite was prepared for hexavalent chromium adsorption from studied water. GCB was characterized by TGA, FTIR, SEM and X-ray diffraction techniques. Wide porous sorptive surface of $3.89 \mathrm{~m}^{2} \mathrm{~g}^{-1}$ and absorptive functionalities of GCB was due to $20 \%(\mathrm{w} / \mathrm{w})$ graphite support on chitosan evidenced from FTIR and SEM that impart maximum adsorption at pH 4, agitation with $200 \mathrm{rpm}$ for $180 \mathrm{~min}$. Adsorption studies revealed intraparticle diffusion models and best-fitted kinetics was pseudo 2nd order one. A wellfitted Langmuir isotherm model suggested monolayer adsorption with an adsorption capacity $\left(q_{\mathrm{m}}\right)$ of $105.6 \mathrm{mg} \mathrm{g}$ and $\boldsymbol{R}^{2}=\mathbf{0 . 9 4 5}$. Sorption mechanisms based on metal ionic interactions, intrusion/diffusion and chemisorptions onto composite. This graphite chitosan binary composite improve sorbent capacity for $\mathrm{Cr}(\mathrm{VI})$.
\end{abstract}

Keywords. Hexavalent chromium; graphite-chitosan composite; adsorption kinetics.

\section{Introduction}

Release of heavy metal in water is a threat to environment and health due to their carcinogenic and mutagenic toxicity [1]. Among heavy metals, chromium is non-biodegradable, bio-available and persists as trivalent and hexavalent species. $\mathrm{Cr}(\mathrm{VI})$ moves readily via soils and water appeared more toxic as it causes lung cancer, besides absorption through skin [2], while $\mathrm{Cr}$ (III) is less toxicity and relatively innocuous. $\mathrm{Cr}$ (VI) generates in waste streams from paints, textile, dyeing, electroplating, metal finishing, power generation, electronic device, leather-tanneries, flyash incinerators, mining, radioactive materials, batteries and pesticides [3]. Environmental protection agency (EPA) ascertained $\mathrm{Cr}(\mathrm{VI})$ limit level for surface water discharge about $100 \mathrm{ppb}$ and in potable water is $50 \mathrm{ppb}$ [4].

Metal contamination can be treated by techniques viz., precipitation; coagulation, adsorption, extraction, ion-exchange, electro-chemical, ultra-filtration and reverse osmosis, etc [5]. These techniques are costly and possess incomplete removal, huge sludge production (disposal problems) and needs quantitative reagent with energy input. Nonetheless, activated carbon used adsorption is effective; but an expensive process to remove chromium [6].

Biopolymers used in metal biosorption found to be superior to adsorption, as viability unaffected by metal uptake and very effective method [7]. Chitin, chitosan and cellulose biopolymer resources are environment-friendly and widely available/agriculture wastes/seafood processing [8]. Recently, chitosan blend with cellulose/glass ceramic/alumina/silica yield composites/hybrids alteration via functionalization and

rsdongre@hotmail.com cross-sectional/morphological changes to enhance its adsorption capacity $[9,10]$. Ubiquitous, after cellulose found in fungi, chitin is 2nd abundant insects, crustaceans and invertebrates as $N$-acetyl-2-amino-2-desoxy-polysaccharide linked ( $\beta 1-4)$ glycosidic framework [11]. Chitosan has oligosaccharides of 2 to 20 units similar to cellulose (except at C-2 position $\mathrm{O}=\mathrm{C}-\mathrm{NH}_{2}$ instead of $-\mathrm{OH}$ ). Weak chemical properties of chitosan can be overcome by surface modification/chemical treatments [12] to articulate $-\mathrm{NH}_{2} /-\mathrm{OH}$ proactive groups for dyes adsorption [13] or metal complextion/diffusion in accessible pore size [14]. In this contest, graphite's hexagonal layers that are well-utilized in heat-resistant/reinforced material $[15,16]$ were exploited to yield inter-wined binary composite for $\mathrm{Cr}(\mathrm{VI})$ removal are developed.

\section{Experimental}

\subsection{Material and methods}

All chemicals were AR grade. Chitosan purchased from Sisco Lab, Mumbai (India) and graphite procured from Loba Chemie, Mumbai (India). Acetic acid (99.5\%, Merck) and ammonium hydroxide (30\%, Merck) are used. Digital $\mathrm{pH}$ meter (Hanna) used and standardized using buffer of $\mathrm{pH} 4$ and 9 (Fisher Scientific) and $\mathrm{pH}$ adjustment done by $0.1 \mathrm{~N}$ $\mathrm{HCl} / \mathrm{NaOH}$ (Fisher Scientific) and Rotary Shaker (Remi make) were used.

\subsection{Synthesis of graphite chitosan binary composite (GCB)}

GCB is synthesized by impregnation method. Chitosan dissolved in $3 \%$ acetic acid and warmed at $50^{\circ} \mathrm{C}$ to obtain gel 
and then graphite $(20 \%, \mathrm{w} / \mathrm{w})$ added and stirred magnetically at NTP for 5-6 h and resultant was sprayed by a syringe in $50 \%$ aqueous ammonia to obtain beads. Finally, beads filtered, washed with distilled water to remove dirt, particulate matter or any colour and dried in oven at $90-105^{\circ} \mathrm{C}$ for $24 \mathrm{~h}$. The beads were grounded in mortar pestle and sieved to get particle size of 175-245 $\mu \mathrm{m}$ (stored in PVC bottles). $\mathrm{Cr}(\mathrm{VI})$ stock solution (1000 $\mathrm{mg}^{-1}$ ) prepared by dissolving potassium dichromate in double-distilled water and diluted in concentration range of $5-100 \mathrm{mg}^{-1}$.

\subsection{Instrumentations and equipments}

Fourier transform infrared (FTIR) performed using Perkin Elmer cast in disks- $\mathrm{KBr}$ pellets $\left(450-4000 \mathrm{~cm}^{-1}\right)$ and XRD on Rigaku MiniFlex-2 Goniometer using $\mathrm{CuK} \alpha(30 \mathrm{kV}$, $15 \mathrm{~mA}$ ). SEM done at accelerating voltage of $15 \mathrm{kV}$ at magnification range of 20 to $5000 \times$ using JSM 6380 . BrunauerEmmett-Teller (BET) surface area was measured using Micromeritics ASAP-2020 V3-04 H. Elemental contents estimated by $\mathrm{C} / \mathrm{H} / \mathrm{N} / \mathrm{S}$ analyzer Vario El Cube at $230 \mathrm{~V}$.

\subsection{Analysis of $\mathrm{Cr}(\mathrm{VI})$ ions by spectrophotometer}

$\mathrm{Cr}(\mathrm{VI})$ residual concentration after adsorption determined by UV-VIS spectrophotometer (7400CE CECIL) at $540 \mathrm{~nm}$ by 1,5 diphenylcarbazide method [17].

\subsection{Batch adsorption studies of graphite chitosan binary $(G C B)$ composite}

Bath adsorption for $\mathrm{Cr}(\mathrm{VI})$ ion $100 \mathrm{ml}$ solution taken in $250 \mathrm{ml}$ Erlenmeyer flasks with suitable amount of adsorbent shaken on rotary shaker followed by filtration using Whatman no.1. The supernatants were analysed for residual
$\mathrm{Cr}(\mathrm{VI})$ ions after contact period of $15,30,60,120,180,240$, 300 and 360 min. $\mathrm{pH}$ effect on $\mathrm{Cr}(\mathrm{VI})$ sorption studied in $\mathrm{pH}$ 2-9 range with GBC at 50-500 ppm. Adsorption isotherms were studied in $\mathrm{Cr}(\mathrm{VI})$ range of $20-100$ ppm with adsorbent dose of $50 \mathrm{ppm}$. Langmuir and Freundlich models were studied.

\subsection{Characterizations}

2.6a Elementary analysis (viz., C/H/N/S/O, \% ash, \% moisture, surface parameters): Elementary analysis of chitosan, graphite and GCB composite are shown in table 1. Ash content determined by known method [18] and calculated by equation (1), \% moisture by gravimetry [19] and water mass/weight difference of wet and dried samples are calculated by equation (2):

$\%$ Ash $=[$ weight of residue $(\mathrm{g}) /$ sample weight $(\mathrm{g})] \times 100$

$\%$ Moisture content $=$ [wet weight $(\mathrm{g})-$ dry weight $(\mathrm{g})] /$ wet weight $(\mathrm{g}) \times 100$.

2.6b Infrared spectra: The free amino and hydroxyl groups get protonated in acidic medium to form $\left(\mathrm{NH}_{3}^{+}\right.$and $\mathrm{OH}_{2}^{+}$), those are capable for $\mathrm{Cr}(\mathrm{VI})$ sorption by charge neutralization [20]. Hence, GBC composite was analysed by FTIR before and after adsorption as shown in figure 1c-d.

The metal ion $\mathrm{Cr}(\mathrm{VI})$ exists as anionic $\mathrm{HCrO}_{4}^{-}$form at $\mathrm{pH} 4$, hence gets strongly adsorbed by chitosan-adsorbent GBC. The main adsorption peak of chitosan-absorbent GBC after adsorption found at $1382 \mathrm{~cm}^{-1}$ that remain unchanged before adsorption (figure $1 \mathrm{~b}, \mathrm{c}$ ). This is due to physical adsorption of $\mathrm{Cr}(\mathrm{VI})$ and not a complexing reaction as reported on cross-linked chitosan beads [21]. Chitosan IR at $3695 \mathrm{~cm}^{-1}$,

Table 1. Characteristics of chitosan, graphite chitosan binary composite (GBC).

\begin{tabular}{|c|c|c|c|}
\hline Analysed parameters & GCB & Pure chitosan & Graphite \\
\hline Ash on ignition $\left(800^{\circ} \mathrm{C}\right)$ & $4.0 \%$ & $2.10 \%$ & $<1.0 \%$ \\
\hline $\mathrm{C} \%$ & $59.35 \%$ & $42.62 \%$ & $>94 \%$ \\
\hline $\mathrm{H} \%$ & $3.9 \%$ & $7.73 \%$ & $4 \%$ \\
\hline $\mathrm{N} \%$ & $3.29 \%$ & $7.98 \%$ & Nil \\
\hline $\mathrm{S} \%$ & $0.155 \%$ & $0.155 \%$ & Nil \\
\hline $\mathrm{O} \%$ & $33.3 \%$ & $33.3 \%$ & $0.001 \%$ \\
\hline Moisture & $1.0 \%$ & $2.90 \%$ & Nil \\
\hline Volatile matter & $55 \%$ & $55 \%$ & Nil \\
\hline Fixed carbon & $33.80 \%$ & $42.62 \%$ & $95 \%$ \\
\hline Particle size & $176-246 \mu \mathrm{m}$ & $75-100 \mathrm{~mm}$ & $50-75 \mu \mathrm{m}$ \\
\hline Density $\left(\mathrm{g} \mathrm{cm}^{-3}\right)$ & $0.988\left(\mathrm{~g} \mathrm{~cm}^{3}\right)$ & $0.20-0.30\left(\mathrm{~g} \mathrm{~cm}^{-3}\right)$ & 2.25 \\
\hline Viscosity & Crystalline particles & $250-600 \mathrm{mPa}$ ( $1 \%$ solution $)$ & Non-viscous \\
\hline Appearance/colour & Dirty white/ash colour & Off-white & Iron-black; luster \\
\hline Solubility & Insoluble in solvents & $1 \%$ acetic acid & Ethanol $<0.2 \%$ \\
\hline Surface area $\left(\mathrm{m}^{2} \mathrm{~g}^{-1}\right)(\mathrm{BET})$ & $3.890 \mathrm{~m}^{2} \mathrm{~g}^{-1}$ & $2.89 \mathrm{~m}^{2} \mathrm{~g}^{-1}$ & $8.0-12.0 \mathrm{~m}^{2} \mathrm{~g}^{-1}$ \\
\hline Total pore volume $\left(\mathrm{cm}^{3} \mathrm{~g}^{-1}\right)$ & 0.002 & 0.014 & $0.1-0.3 \mathrm{P} / \mathrm{P} 0$ \\
\hline Mean pore diameter (nm) & 28.12 & 10.40 & - \\
\hline
\end{tabular}


$3073 \mathrm{~cm}^{-1}$ and $2800-2950 \mathrm{~cm}^{-1}$ assigned for $-\mathrm{OH}$ stretching, while at $1667 \mathrm{~cm}^{-1}$ due to $\mathrm{C}=\mathrm{O}$ stretching in amide and at $1152 \mathrm{~cm}^{-1}$ for bridge-O-stretching. The IR bands at $1262 \mathrm{~cm}^{-1}$ attributed for $\mathrm{C}-\mathrm{O}-\mathrm{H}$ stretching and broad IR at $1077 \mathrm{~cm}^{-1}$
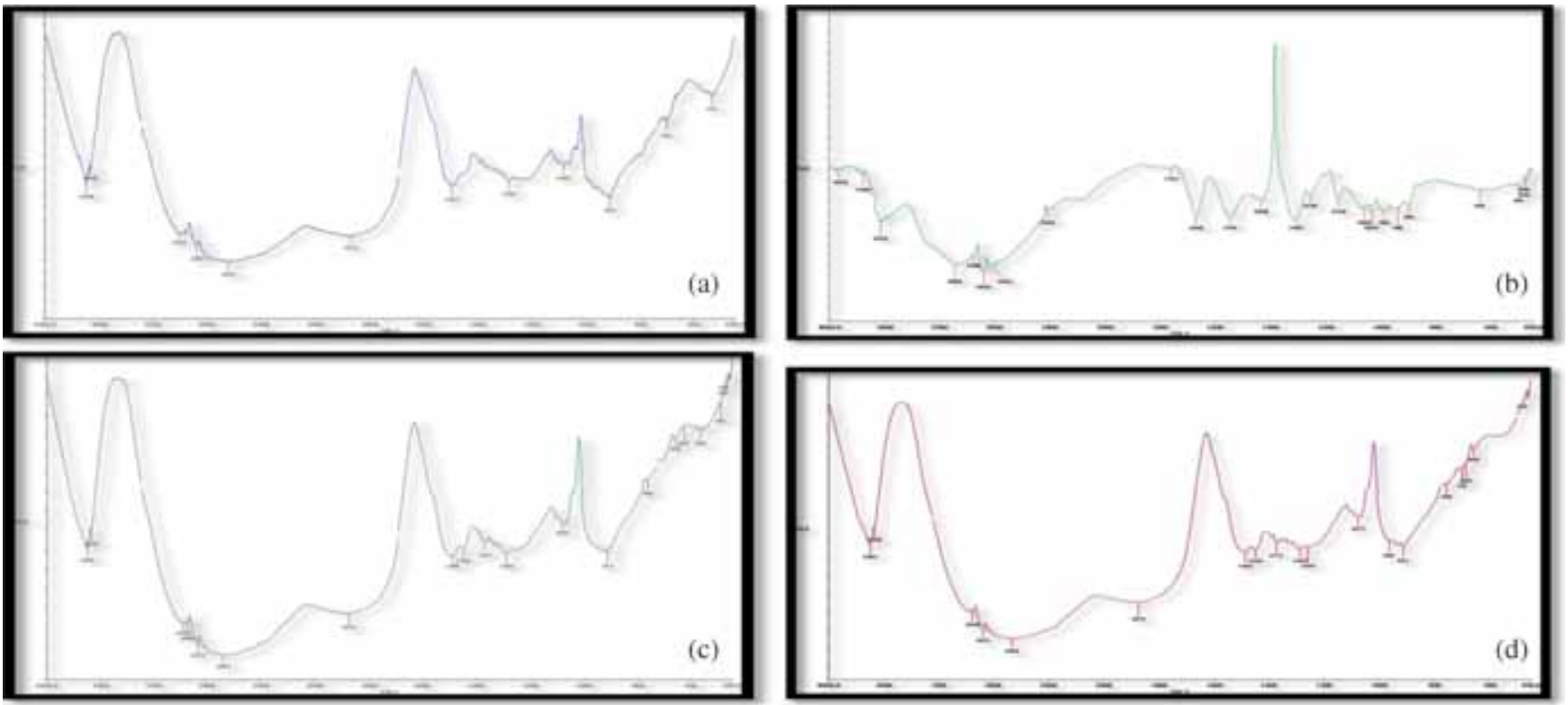

Figure 1. FTIR of (a) graphite, (b) chitosan, (c) GBC before and (d) after $\mathrm{Cr}(\mathrm{VI})$ adsorptions.
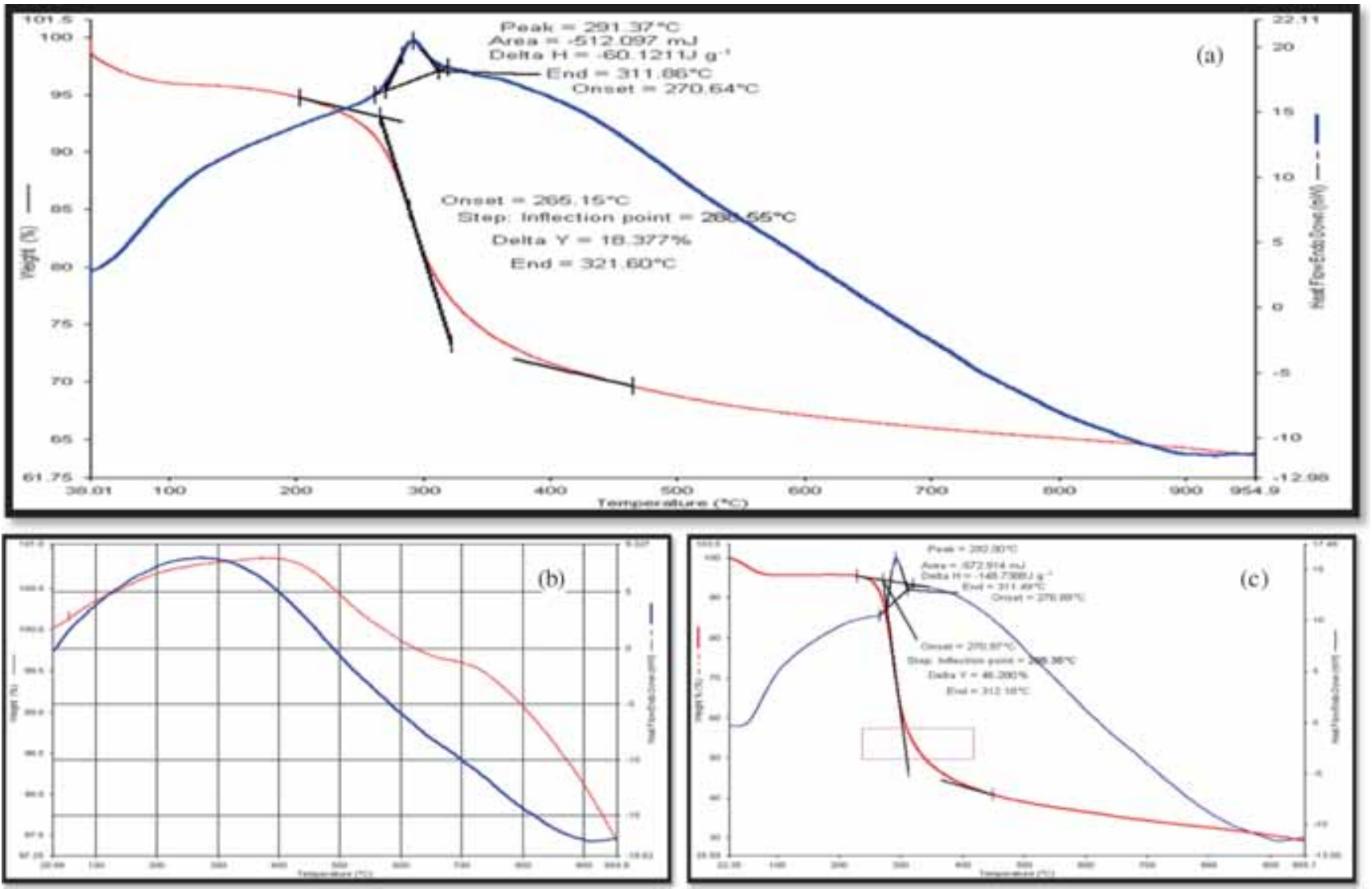

Figure 2. TGA of (a) graphite, (b) chitosan and (c) GBC composite. 
graphite. After $\mathrm{Cr}(\mathrm{VI})$ uptake by GCB, the band shifted from 2872 to $2875 \mathrm{~cm}^{-1}$, supports -OH link with $\mathrm{Cr}(\mathrm{VI})$ [20].

2.6c Thermogravimetric analysis (TGA): TGA is used to determine decomposition temperature of materials. GBC composite exhibited 1st decomposition at $38^{\circ} \mathrm{C}$ which continued until $200^{\circ} \mathrm{C}$ with $5 \%$ weight loss due to evaporation of water and 2 nd decomposition at $265.15^{\circ} \mathrm{C}$ and continued to $321.6^{\circ} \mathrm{C}$ with $18.37 \%$ weight chitosan loss and maximum degradation at $288.55^{\circ} \mathrm{C}$, which ends at $954.9^{\circ} \mathrm{C}$ with total $35 \%$ weight loss of chitosan skeleton. Nevertheless, two exothermic peaks of GBC namely at 292 and $270.89^{\circ} \mathrm{C}$, respectively, shown in figure $2 \mathrm{c}$ indicated less thermal stability of GBC composite than pure graphite, figure $2 \mathrm{~b}$, instead more stable than pure chitosan (figure $2 \mathrm{c}$ ).

2.6d Scanning electron microscope (SEM) analysis: SEM well exhibits visual confirmation of physical state [23] and surface morphology of the graphite, chitosan and GCB composite to measure porosity and particle size dimensions. SEM images at magnifications show that chitosan microparticles are spherical with a slightly wrinkled surface and nonporous, uneven granular structure shown in figure 3c. SEM of graphite exhibited individual needle-shaped particles with intrinsic flake morphology shown in figure 3d. GCB composite SEM changes in crystal shape, morphology and agglomerated structure with particle size range of 175$246 \mu \mathrm{m}$ (pore volume $28.12 \mathrm{~nm}$ ) exhibited irregular surfaces and rugosity due to inter-wined/cross-linking and fractures different than non-homogenous chitosan surfaces shown in figure $3 a$ and $b$. GCB entirely differs from chitosan and graphite as it supported solid reinforcement in chitosan and alter surface properties [24].

2.6e XRD analysis: XRD of chitosan, graphite and GCB composite are illustrated in figure $4 \mathrm{a}-\mathrm{c}$, respectively. Chitosan XRD exhibited broad diffraction peaks at $2 \theta=10$, 20.2 and $20.74^{\circ}$ with d-spacing of $4.2 \AA$ as characteristic fingerprints of semi-crystallinity [25] and no impurity peaks observed. GCB showed a diffraction peak at $2 \theta=26.5^{\circ}$ (with d-spacing of about $3.35 \AA$ ) due to graphite reinforcement [26] indicated single phase composition. While GCB composite showed broad peak at $2 \theta=20^{\circ}$ due to the chitosan decreased in intensity after doping with graphite and confirms reinforcement in chitosan. Broaden small peaks around $2 \theta=18-22^{\circ}$ and a few peaks at $2 \theta=40$ and $44^{\circ}$ in GCB showed successful inter-wined graphite layer in chitosan to provide an auxiliary surface support and a high degree of crystallinity [27].

\section{Results and discussion}

\subsection{Adsorption isotherms}

Langmuir and Freundlich models used for isothermal study as presented in table 2 and figures 5 and 6 . The isotherms from regression analysis depicted $\mathrm{Cr}(\mathrm{VI})$ equilibrium at composite boundary.
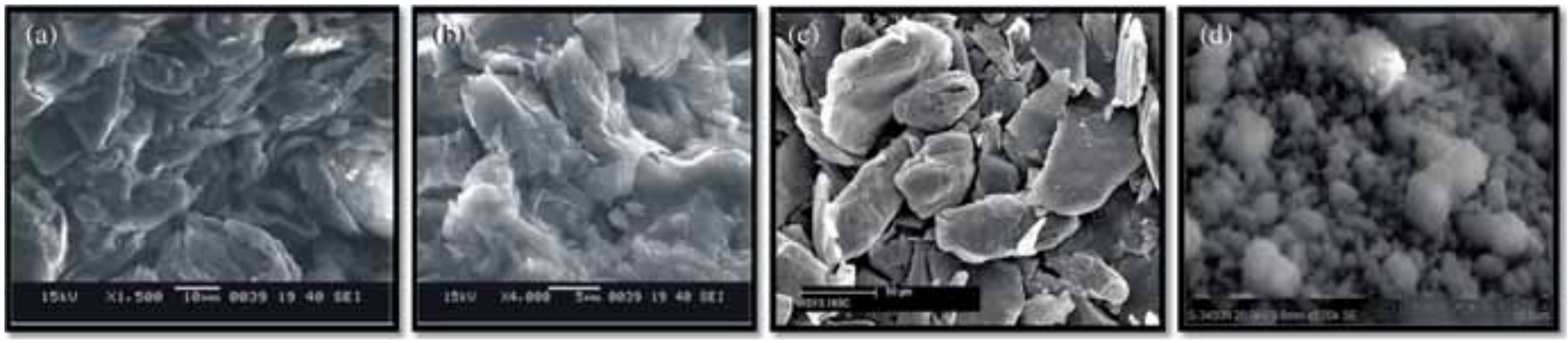

Figure 3. SEM images of GCB composite at (a) $1500 \times$, (b) $4000 \times$, (c) graphite at $250 \times$ and (d) chitosan skeleton at $5000 \times$.
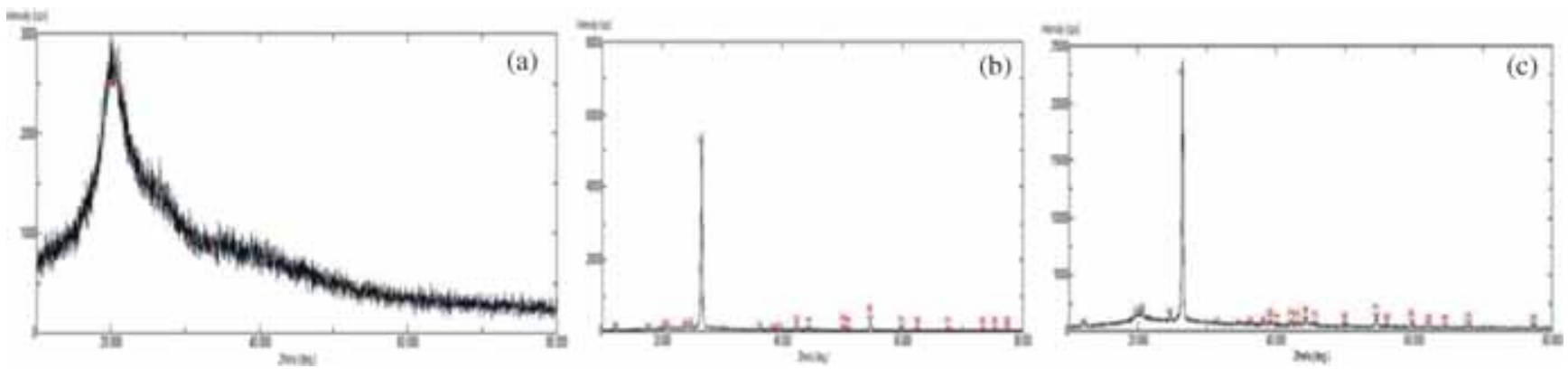

Figure 4. Powder XRD patterns of (a) chitosan, (b) graphite and (c) GCB composite. 
Table 2. Linear equations, parameters for $\mathrm{Cr}(\mathrm{VI})$ adsorption onto GCB composite.

\begin{tabular}{|c|c|c|c|c|c|c|c|c|}
\hline \multirow{2}{*}{$\begin{array}{l}\text { Equillibrium models } \\
\text { Parameters }\end{array}$} & \multicolumn{4}{|c|}{ Langmuir constants } & \multicolumn{4}{|c|}{ Freundlich constants } \\
\hline & $Q_{\max }\left(\mathrm{mg} \mathrm{g}^{-1}\right)$ & $b\left(1 \mathrm{mg}^{-1}\right)$ & $R^{2}$ & $k$ & $R_{\mathrm{L}}$ & $K_{\mathrm{f}}$ & $1 / n$ & $R^{2}$ \\
\hline Value & 105 & 0.367 & 0.943 & 0.966 & $0.028-0.076$ & 3.564 & 0.151 & 0.807 \\
\hline
\end{tabular}

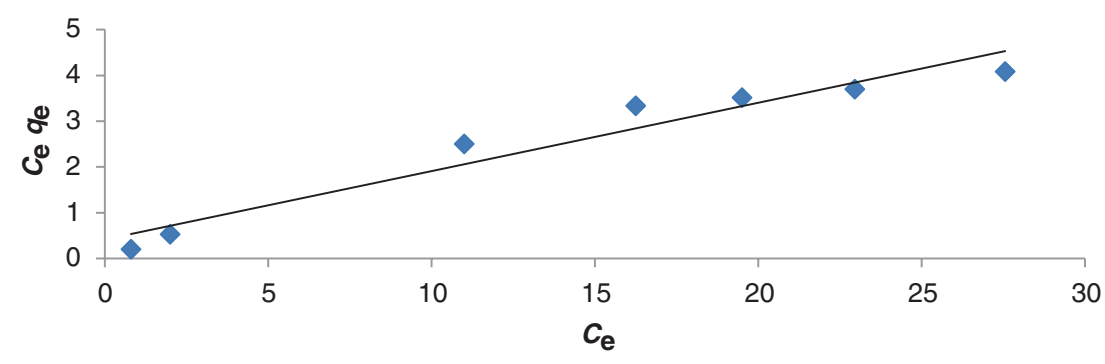

Figure 5. Langmuir adsorption isotherm.

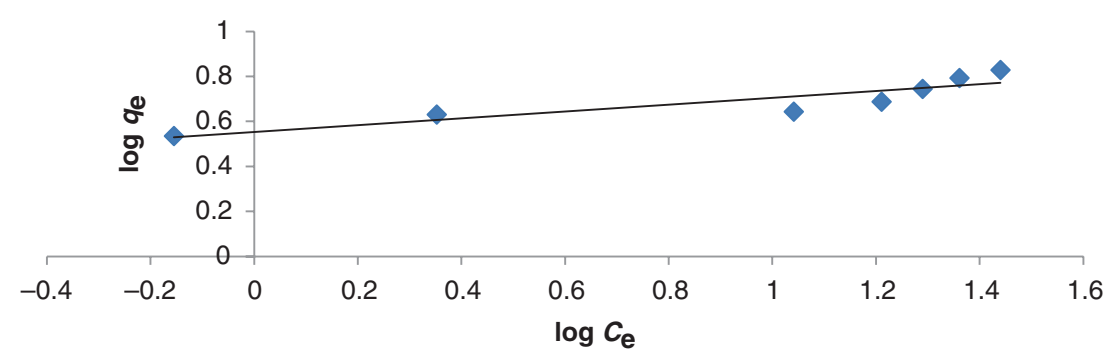

Figure 6. Freundlich adsorption isotherm.

$R_{\mathrm{L}}$ value expresses essential characteristics of isotherm model and defined by equation (3) given below:

$$
\frac{C_{\mathrm{e}}}{q_{\mathrm{e}}}=\frac{1}{q_{\mathrm{m}} K_{\mathrm{L}}}+\frac{1}{q_{\mathrm{m}}} C_{\mathrm{e}},
$$

where $C_{\mathrm{e}}=$ concentration of $\mathrm{Cr}(\mathrm{VI})$ in solution at equilibrium $\left(\mathrm{mg} \mathrm{l}^{-1}\right) . q_{\mathrm{e}}$ is the amount of $\mathrm{Cr}(\mathrm{VI})$ adsorbed at equilibrium $\left(\mathrm{mg} \mathrm{g}^{-1}\right)$ and calculated by equation

$$
q_{\mathrm{e}}=\left(C_{0}-C_{\mathrm{e}}\right) V / m
$$

where $C_{0}$ is initial concentration of $\mathrm{Cr}(\mathrm{VI})$ in solution $\left(\mathrm{mg} \mathrm{l}^{-1}\right), C_{\mathrm{e}}$ is concentration of $\mathrm{Cr}(\mathrm{VI})$ in solution at equilibrium $\left(\mathrm{mg} \mathrm{l}^{-1}\right), m$ is mass of adsorbent used $(\mathrm{g})$ and $V$ is volume of $\mathrm{Cr}(\mathrm{VI})$ solution (L) taken. Adsorption gets favourable if $0<R_{\mathrm{L}}<1$ and for $R_{\mathrm{L}}>1$, it is unfavourable, but for $R_{\mathrm{L}}=1$ and $R_{\mathrm{L}}=0$, its linear and irreversible, respectively, [28] based on assumptions [29] that $\mathrm{Cr}(\mathrm{VI})$ are adsorbed at defined adsorbent sites and each site can hold single $\mathrm{Cr}(\mathrm{VI})$, besides all sites are equivalent in thermodynamics and kinetics. If initial $\mathrm{Cr}(\mathrm{VI})$ concentration rise, then adsorption enhanced till binding sites get saturated. $R^{2}$ and $R_{\mathrm{L}}$ in the range of 0-1 showed applicability/fit of Langmuir model. Adsorption capacity $q_{\mathrm{m}}$ and $b$ ( $b=$ ratio of $C_{\mathrm{e}} / q_{\mathrm{m}}$, where $q_{\mathrm{m}}$ is maximum adsorption capacity of adsorbent) were $105 \mathrm{mg} \mathrm{g}^{-1}$ and $0.367 \mathrm{l} \mathrm{mg}^{-1}$, respectively, for GCB composite compared with biosorbents in table 2 [30,31]. Adsorption capacity of chitosan for $\mathrm{Cr}(\mathrm{VI})$ reported $23 \mathrm{mg} \mathrm{g}^{-1}$ [32] under similar conditions.

\subsection{Kinetics of adsorption}

Adsorption is controlled by kinetics [32] and estimation of sorption rates guides sorption mechanisms. Thus, pseudo 1 st and 2nd order kinetics intraparticle diffusion were investigated as given in equations (3-9) and shown in figures 7-9:

$$
\ln \left(q_{\mathrm{e}}-q_{f}\right)=\ln q_{\mathrm{e}}-k_{1} t \quad \text { pseudo } 1 \text { st order model. }
$$

Using equation (2), $\ln \left(q_{\mathrm{e}}-q_{\mathrm{t}}\right)$ vs. $t$ plotted and pseudo 2 nd order model, rate-limiting step is surface adsorption involved chemisorption, where removal of metal from solution is due to physicochemical interactions [32] as mentioned in figure 9 . The kinetic parameters are calculated by equations (5-8).

$$
\begin{aligned}
& \left(t / q_{\mathrm{t}}\right)=\left(1 / k_{2} / q_{\mathrm{e}^{2}}\right)+\left(1 / q_{\mathrm{e}} t\right), \\
& \frac{1}{q_{\mathrm{e}}}=\frac{1}{q}+\left(\frac{1}{k_{2} q_{\mathrm{e}^{2}}}\right) \frac{1}{t}, \\
& q_{\mathrm{e}}=q_{\mathrm{t}}-\left(\frac{1}{k q_{\mathrm{t}}}\right) \frac{q}{t}, \\
& \frac{q_{\mathrm{e}}}{t}=k q_{\mathrm{t}}^{2}-k q_{\mathrm{e}} q_{\mathrm{t}} .
\end{aligned}
$$




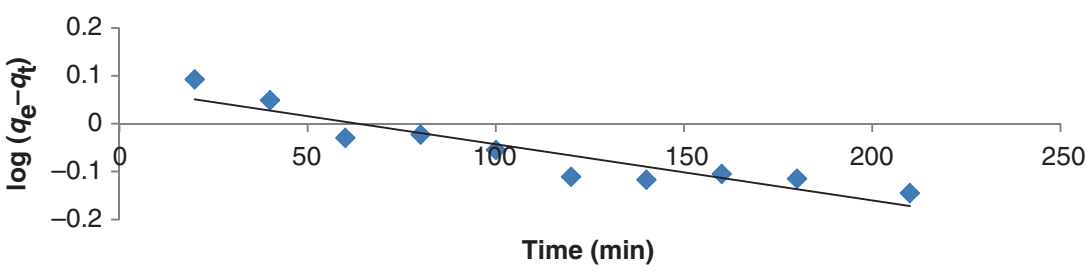

Figure 7. Pseudo first-order kinetic plot for removal of $\mathrm{Cr}(\mathrm{VI})$ by composite.

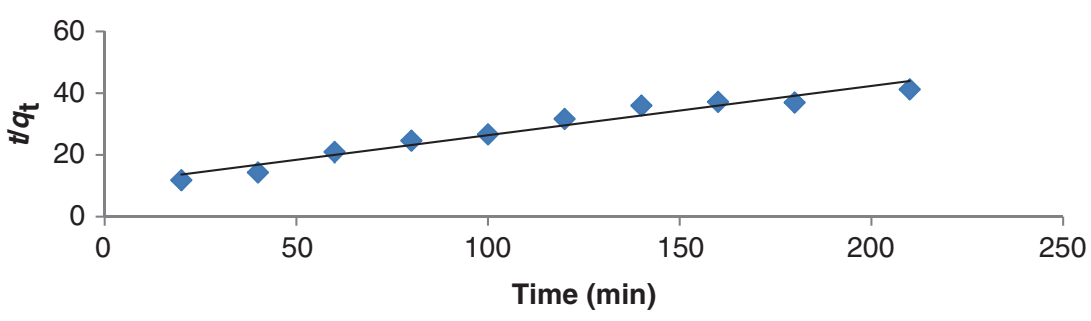

Figure 8. Pseudo second-order kinetic plot for removal of $\mathrm{Cr}(\mathrm{VI})$ by composite.

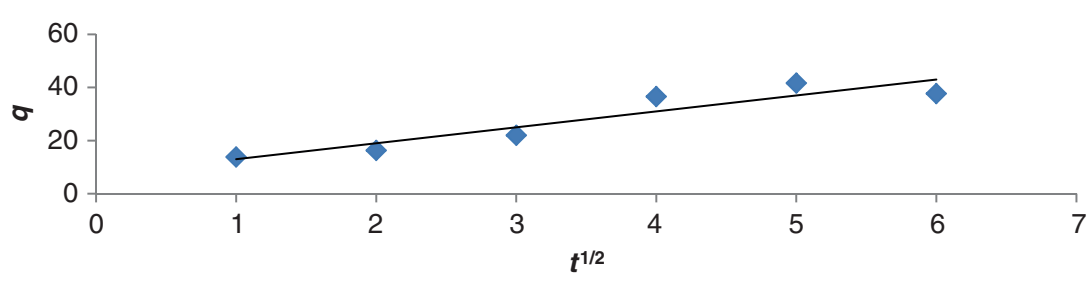

Figure 9. Intraparticle diffusion model kinetics for removal of $\mathrm{Cr}(\mathrm{VI})$ by composite.

The intraparticle diffusion model explains that adsorption depends on speed at which adsorbate/Cr(VI) diffuses towards composite (i.e., diffusion-controlled) presented in equation (9):

$$
q_{\mathrm{e}}=k_{3} t^{1 / 2}+c,
$$

where $k_{3}$ is a rate constant of intraparticle transport $\left(\mathrm{g} \mathrm{mg}^{-1}\right.$ $\min ^{-1}$ ) and $c$ is intercept [33] and presented in figure 9 . The adsorption equilibrium reached within 180 min, maximum $92 \%$ removal of $\mathrm{Cr}(\mathrm{VI})$ adsorbed with extremely slow diffusion from surface into pores, which were least accessible sites for adsorption [32]. The coefficient $R^{2}=0.95$ by pseudo 2 nd order is higher than $R^{2}=0.93$, by pseudo 1 st order and $R^{2}=0.91$ by intraparticle diffusion. Similarly, high $k_{2}$ obtained by pseudo 2 nd order suggested rapid sequestered by composite functionalities results quick equilibrium. So, adsorbent/composite and adsorbate/Cr(VI) ratio are governing rate-determining step, suggested chemical adsorption/chemisorptions [32,33].

\subsection{Effect of $p H$}

Adsorption depends on ionic state of functionalities at the adsorbent's surface that gets changed with $\mathrm{pH}$ [34], thus, sorption studied in $\mathrm{pH} 2-9 \% \mathrm{Cr}(\mathrm{VI})$ removal enhanced as $\mathrm{pH}$ raise from 2 to 5.5 , and more removal under acid conditions

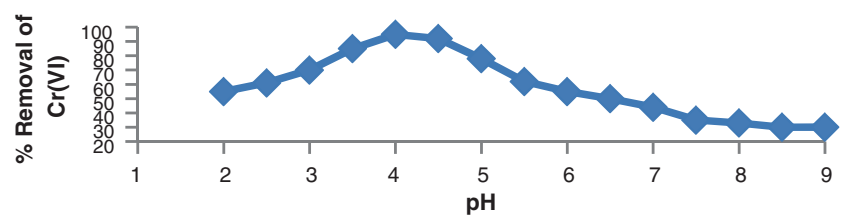

Figure 10. Effect of $\mathrm{pH}$ on $\%$ removal of $\mathrm{Cr}(\mathrm{VI})$ ions (initial concentration: $25 \mathrm{mg} \mathrm{l}^{-1}$; temperature: $27^{\circ} \mathrm{C}$; agitation speed: $200 \mathrm{rpm}$; contact time: $180 \mathrm{~min}$; adsorbent dose: $5 \mathrm{~g} \mathrm{l}^{-1}$; $\mathrm{pH} 4$ ).

is shown in figure 10. But, adsorption decreased at $\mathrm{pH}>5.5$ is considered as poor under basic conditions indicated characteristic chemisorptions due to few competitive protons sorption [32,35]. At acidic $\mathrm{pH}=3-5.5, \mathrm{HCrO}_{4}^{-}$and $\mathrm{Cr}_{2} \mathrm{O}_{7}^{2-}$ anions are predominant, but at acidic $\mathrm{pH}<2.5, \mathrm{Cr}_{3} \mathrm{O}_{10}^{-}$and $\mathrm{Cr}_{4} \mathrm{O}_{13}^{2-}$ are dominated in equilibrium [35]. $\mathrm{HCrO}_{4}^{-}$anions interacted strongly with positive charges located on surface composites sites which get decreased at acidic $\mathrm{pH}$ $<2.5$. $\mathrm{Cr}(\mathrm{VI})$ gets maximum adsorbed at $\mathrm{pH} 3.5-5.5$ range, so, kept $\mathrm{pH}=4$ as optimum throughout. The electrostatic binding sites corresponding polymerized chromium anionic species decrease in basic $\mathrm{pH}$, consequently adsorption gets decreased. Besides, at $\mathrm{pH}>7$, the composite surface gets negatively charged and subsequently enhanced electrostatic repulsion between $\mathrm{Cr}(\mathrm{VI})$ ions and charges at adsorbent sites, leads to release of adsorbed $\mathrm{Cr}(\mathrm{VI})$ off GCB composite [36]. 


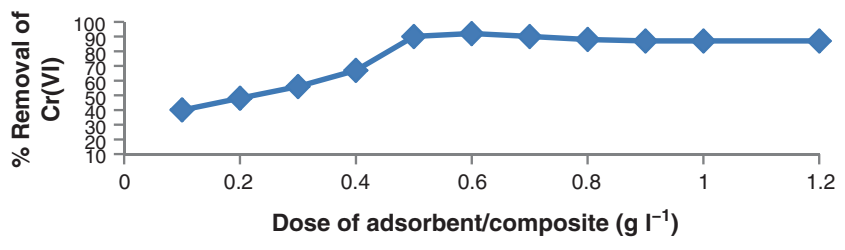

Figure 11. Effect of adsorbent dose on \% removal of $\mathrm{Cr}(\mathrm{VI})$ (Cr(VI) concentration: $25 \mathrm{mg}^{-1}$; temperature: $27^{\circ} \mathrm{C}$; agitation: $200 \mathrm{rpm}$; contact time: $180 \mathrm{~min}$; adsorbent dose: $5 \mathrm{~g} \mathrm{l}^{-1}$; $\mathrm{pH} 4$ ).

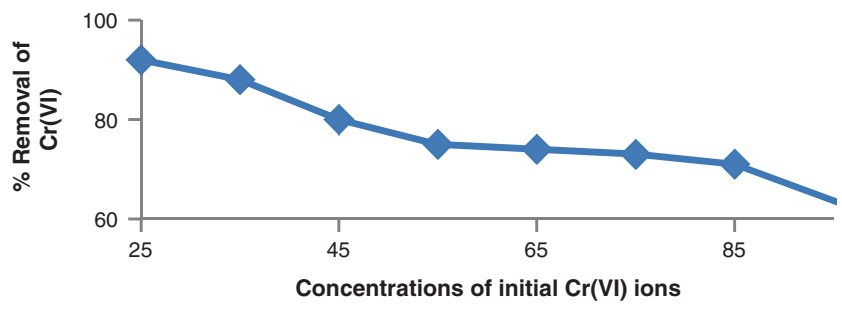

Figure 12. Effect of initial $\mathrm{Cr}(\mathrm{VI})$ ion concentration on \% removal (temperature: $27^{\circ} \mathrm{C}$; agitation: $200 \mathrm{rpm}$; contact time: 180 min; adsorbent dose: $5 \mathrm{~g} \mathrm{l}^{-1}$; $\left.\mathrm{pH} 4\right)$.

\subsection{Effect of adsorbent dose (GCB)}

The $\%$ graphite functionalized on chitosan yields composite which differs adsorption capacity/efficiency with varying dose of GCB under the optimal conditions as illustrated in figure 11. As increase in GCB dosage from 0.1 to $0.6 \mathrm{~g}^{-1}$, removal efficiency augmented from 42 to $92 \%$ (49$105 \mathrm{mg} \mathrm{g}^{-1}$ for $5 \mathrm{mg} \mathrm{l}^{-1}$ ). Adsorption efficiency rises due to availability of amino/hydroxyl proactive groups responsible for sorption and at lower dose metal : adsorbent ratio is decreased. Besides $\mathrm{Cr}(\mathrm{VI})$ removal is not linearly proportionate to increase in adsorbent dose $\left(>0.6 \mathrm{~g} \mathrm{l}^{-1}\right)$, instead remains steady, as attributed to interference between binding sites [37].

\subsection{Effect of initial Cr(VI) concentration}

Effects of initial $\mathrm{Cr}(\mathrm{VI})$ concentration, in $25-95 \mathrm{mg}^{-1}$ range, on adsorption is studied and shown in figure 12. The initial $\mathrm{Cr}(\mathrm{VI})$ concentration provides driving force to overcome all mass transfer resistance of metal between aqueous and solid phase [38], thus, if initial $\mathrm{Cr}(\mathrm{VI})$ concentration increases from 25 to $100 \mathrm{mg} \mathrm{l}^{-1}$, and $\mathrm{Cr}(\mathrm{VI})$ adsorption decreased from 92 to $50 \%$ (overall $45 \%$ reduction). At optimum 25 ppm concentration of $\mathrm{Cr}(\mathrm{VI})$, active binding sites gets unsaturated and offered large surface area for adsorption, but at higher concentration, accumulation of adsorbent particles escorts decrease total surface area is a cause for adsorption reduction with increasing initial $\mathrm{Cr}(\mathrm{VI})$ concentration gradient, matches to reported findings [35].

\subsection{Effect of contact time}

The effect of contact time on \% removal has a linear impact over a span of $3 \mathrm{~h}$ and $75-80 \%$ increase in $\mathrm{Cr}(\mathrm{VI})$ ions adsorption observed in $180 \mathrm{~min}$ achieved at $200 \mathrm{rpm}$ as shown in figure 13. Since, optimized contact time facilitates proper contact with composite binding sites to promote transfer of $\mathrm{Cr}(\mathrm{VI})$. At 120 and $150 \mathrm{rpm}, \mathrm{Cr}(\mathrm{VI})$ adsorption found slightly lower than optimized agitation time, $180 \mathrm{~min}$, but adsorption found steady $>180 \mathrm{~min}$. These results indicate that contact between solid and liquid is more effective at agitation for $180 \mathrm{~min}$ (kept throughout experiments) agrees with reported results in literature $\mathrm{Cr}(\mathrm{VI})$ sorptions [38].

\subsection{Effect of agitation speed}

In batch adsorption systems, agitation speed plays a vital role affecting the external boundary film and the distribution of the metal ions in the bulk solution [22]. The effect of agitation speed on $\mathrm{Cr}(\mathrm{VI})$ adsorption examined at $100-300 \mathrm{rpm}$ (figure 14). $\mathrm{Cr}(\mathrm{VI})$ adsorption found to be lower at agitation

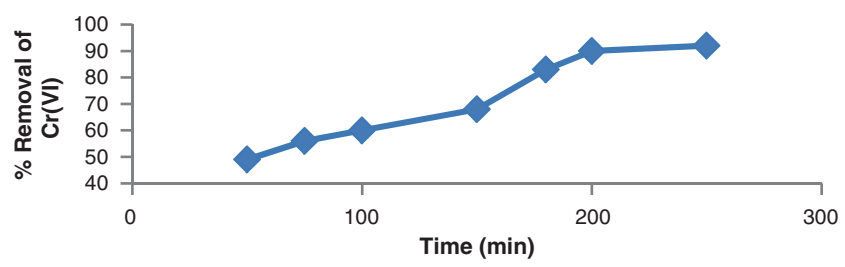

Figure 13. Effect of contact time on \% removal of $\mathrm{Cr}(\mathrm{VI})$ ions

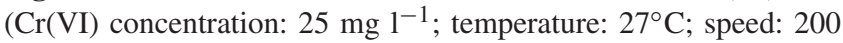
rpm; adsorbent: $\left.5 \mathrm{~g} \mathrm{l}^{-1} ; \mathrm{pH} 4\right)$.

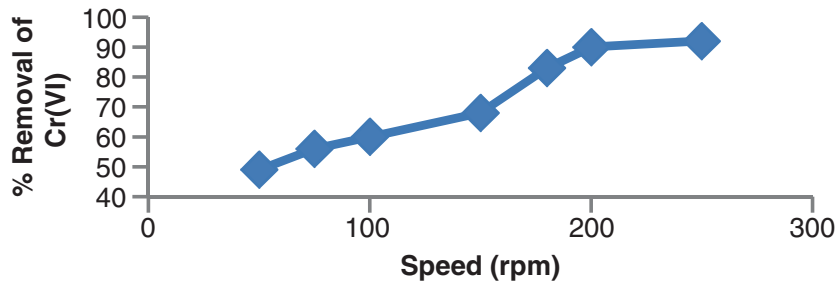

Figure 14. Effect of agitation speed on \% removal of $\mathrm{Cr}(\mathrm{VI})$ ions (Cr(VI) concentration: $25 \mathrm{mg}^{-1}$; temperature: $27^{\circ} \mathrm{C}$; time 180 min; adsorbent: $5 \mathrm{~g} \mathrm{l}^{-1}$; $\left.\mathrm{pH} 4\right)$.

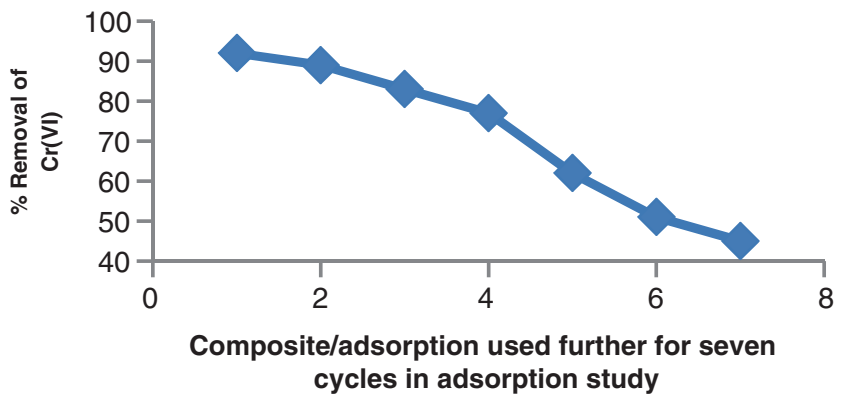

Figure 15. Regeneration of composite used in total seven cycles. 
speed of 50, 100 and $150 \mathrm{rpm}$, but enhanced at $180 \mathrm{rpm}$ and remains steady at $>200 \mathrm{rpm}$. $\mathrm{Cr}(\mathrm{VI})$ removal efficiency not changed notably $>200 \mathrm{rpm}$ (optimal speed) as attributed to little resistance of boundary layer and high mobility of the system [39].

\subsection{Regeneration of adsorbent/composite}

Regeneration/desorption studies performed at $\mathrm{pH}=8$ are shown in figure 15. Initial electrostatic metal bindings onto amino/hydroxyl/active sites of chitosan composite gets weakened in basic $\mathrm{pH}$ due to competition with $\mathrm{OH}[35,40]$. Literature too supports decreased $\mathrm{Cr}(\mathrm{VI})$ removal efficiency at $\mathrm{pH}>7$ presumably due to inactivity of proactive composite sites [32]. Above $\mathrm{pH}>7$, ions chemisorption gets decreased as chitosan undergoes deprotonation [35,41] and composite gets negatively charged above $\mathrm{pH} 7.5$, so repelled/release off from composite [42].

GCB composite can be reused up to seven adsorption cycles with mere $44 \%$ reduction in $\mathrm{Cr}(\mathrm{VI})$ adsorption capacity and compared with other chitosan-based adsorbents in table 3 .

\subsection{Sorption mechanism}

The metal $\mathrm{Cr}(\mathrm{VI})$ sorption onto GCB composite was screened to evaluate adsorption kinetics and isothermal analysis that is represented in table 2. The important kinetic constants were calculated by applying pseudo 1st order, 2nd order and intraparticle diffusion models using equations

Table 3. Adsorption capacities of different adsorbents for chromium (VI) [35,38-40].

\begin{tabular}{lccc}
\hline Adsorbents & $\begin{array}{c}\text { Max. sorption } \\
\text { capacity }\left(\mathrm{mg} \mathrm{g}^{-1}\right)\end{array}$ & $\begin{array}{c}\text { pH } \\
\left.\text { ions ( } \mathrm{mg} \mathrm{g}^{-1}\right)\end{array}$ \\
\hline Pure chitosan only & 27.2 & 6 & 800 \\
Cross-linked chitosan & 50.0 & 5.0 & 1000 \\
Metal-imprinted chitosan & 51.0 & 5.5 & 1000 \\
Chitosan cross-linked epichlorohydrin & 52.3 & 5.5 & 1000 \\
Metal chitosan epichlorohydrin & 51.0 & 5.5 & 1000 \\
GCB, this research study & $153.8^{\mathrm{a}}$ & 4.0 & 105 \\
\hline
\end{tabular}

${ }^{a}$ Based on graphite $(20 \%$, w/w) on chitosan (corresponds to max. capacity of $\left.105.4 \mathrm{mg} \mathrm{g}^{-1} \mathrm{GCB}\right)$.

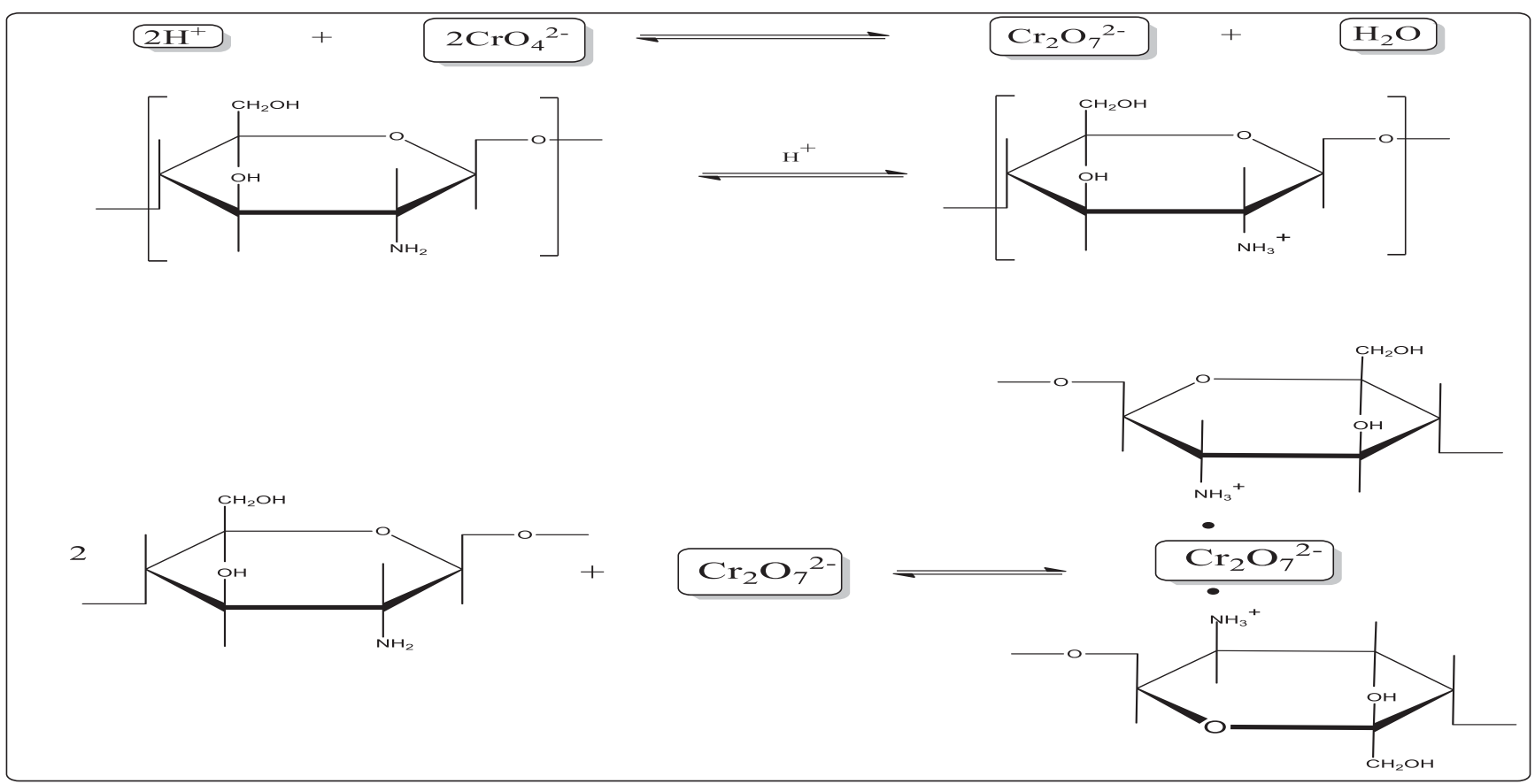

Figure 16. Mechanism of $\mathrm{Cr}(\mathrm{VI})$ sorption from water on GCB composite. 
(4-9). The well-fitted Langmuir isotherm model showed an adsorption capacity $\left(q_{\mathrm{m}}\right)$ of $105.6 \mathrm{mg} \mathrm{g}^{-1}$ and $R^{2}=0.945$ suggested $\mathrm{Cr}(\mathrm{VI})$ sorption in GCB is a monolayer adsorption phenomena due to throughout homogeneous distribution of metal-composite coordination unit. Besides, rate of $\mathrm{Cr}(\mathrm{VI})$ adsorption is initially rapid, which then gradually gets steady with time (figure 14), and subsequently removal time is less for higher $\mathrm{Cr}(\mathrm{VI})$ ions concentration. The experimental adsorption capacity $\left(q_{\mathrm{e}}\right)$ found to be $\sim 105 \mathrm{mg} \mathrm{g}^{-1}$ for GCB composite as close to theoretical capacity that substantiates kinetics fitted well with the pseudo-second-order model as reported values by diverse materials [35]. This physical adsorption of $\mathrm{Cr}(\mathrm{VI})$ onto GCB has critically influenced under mild acidic conditions, i.e., $\mathrm{pH}=4$ favours and more efficient than neutral/higher $\mathrm{pH}$ as shown in figure 11 and also highlighted in reports [35]. This is due to $\mathrm{pH}$ dependency of varied $\mathrm{Cr}(\mathrm{VI})$ anionic species present in aqueous solution as chromate ion on lowering $\mathrm{pH}=4$ changes to orange colour dichromate ion which is subsequently grabbed by protonated $-\mathrm{NH}_{3}^{+} / \mathrm{OH}_{2}^{+}$groups of $\mathrm{GCB}$ as shown in figure 16.

\section{Conclusions}

This study reported an efficient reductive removal of toxic $\mathrm{Cr}(\mathrm{VI})$ ions from aqueous solution employing easily synthesized GCB composite. The study was carried out by varying parameters viz., initial $\mathrm{Cr}(\mathrm{VI})$ ions, adsorbent dose, $\mathrm{pH}$, agitations speed, contact time and adsorption models. The pseudo second-order kinetics and Langmuir model were best suited to describe adsorption equilibrium. The $-\mathrm{OH},-\mathrm{NH}_{2}$ and $-\mathrm{C}-\mathrm{O}-\mathrm{C}$ functionalities of chitosan gets inter-wined with graphite in GCB composite exchanges. $\mathrm{Cr}(\mathrm{VI})$ anions from water with removal capacity of $105 \mathrm{mg} \mathrm{g}^{-1}$ found at $\mathrm{pH} \sim 4$, achieved in $3 \mathrm{~h}$. The removal mechanism has also been demonstrated and GCB composites were reused in seven-fold cycle. Therefore, GCB is efficient matrix for the reductive removal of environmentally toxic and hazardous $\mathrm{Cr}(\mathrm{VI})$ as newer approach towards remediation of heavy metals from wastewater.

\section{Acknowledgements}

I am thankful for the supports from Head of the department of chemistry; RTM Nagpur University, Nagpur, to carry out this research and to Ms Asha $\mathrm{H}$ Gedam for graphical work. Compliance with ethical standards research involved no human participants and/or animals.

\section{References}

[1] Kortenkamp A, Shayer R O and Woodbrige N 1996 Arch. Biochem. Biophys. 329199
[2] Giwa A A, Olajire A, Oladipo M A, Bello M O and Bello I A 2013 Inter. J. Sci. Eng. Res. 41275

[3] Nieboer E, Jusys A A, Nriagu J O and Nieboer E 1999 Biologic chemistry of chromium, in: Chromium in Natural and Human Environments (New York: Wiley Inter-Science) p 3

[4] U.S. EPA 1990 Draft manual of practice identification of illicit connections U.S. EPA Permits Division (EN-336)

[5] Yan G and Viraraghavan T 2001 Biores. Technol. 78243

[6] Benito Y and Ruiz M L 2002 Desalination 142229

[7] Volesky B and Holan Z R 1995 Biotech. Prog. 11235

[8] Xiaoqi S, Bo P, Ji C and Deqian C L 2009 Am. Inst. Chem. Eng. 552062

[9] Peter M, Binulal N S, Soumya S, Nair S V, Furuike T, Tamura $\mathrm{H}$ et al 2010 Carbohydr. Polym. 79284

[10] Gandhi M R, Viswnathn N and Meenakshi S 2010 Int. J. Biol. Macromol. 47146

[11] Xi F, Wu J and Lin J X 2006 J. Chroma 112538

[12] Crini G and Badot P M 2008 Prog. Polym. Sci. 33399

[13] Synowiecki J and Al-Khateeb N A 2003 Crit. Rev. Food Sci. Nutri. 43145

[14] Azlan K, Wan-Saime W N and Lai-Ken L 2009 J. Environ. Sci. 21296

[15] Fitzer E 1987 Carbon 25163

[16] Chauhan A, Chauhan P and Kaith B 2012 J. Chem. Eng. Process. Technol. 31

[17] Eaton A D, Clesceri L S and Greenberg A E 1995 Standard methods for the examination of water and wastewater, 19th edn. (Washington: American Public Health Association) p 1325

[18] AOAC 1990 Method of analysis, 15th edn. (Washington: Association of Analytical Chemist) p 312

[19] Black C A 1965 Methods of soil analysis. Part I: Physical and mineralogical properties. (Madison: Wisconsin American Society of agronomy) p 671

[20] Wan Ngah W S, Kamari A, Fatinathan S and Ng P W 2006 Adsorption 12249

[21] Qian S, Huang G, Jiang J, He F and Wang Y 2000 J. Appl. Polym. Sci. 773216

[22] Yeh J T, Chen C L and Huang K S 2007 Mater. Lett. 611292

[23] Yen M T, Yang J H and Mau J L 2009 Carbohydr. Polym. 7515

[24] Trimukhe K D and Varma A J 2008 Carbohydr. Polym. 71698

[25] Kong L, Gao Y, Gong Y, Zhao N and Zhang X $2005 \mathrm{~J}$. Biomed. Mater. Res. 75275

[26] Irfan M, Yim J H, Kim C and Jho Y D 2013 Appl. Phys. Lett. 103201108

[27] Ebru G, Dilay P, Cuney H, Unlu O A and Nurfer G 2007 Carbohydr. Polym. 67358

[28] Chong K H and Volesky B 1995 Biotech. Bioeng. 47451

[29] Langmuir I 1918 J. Am. Chem. Soc. 401361

[30] Schmuhl R, Krieg K M and Keizer K 2001 Water SA 271

[31] Batista A C L, Villanueva E R and Campos T G M 2011 Molecules 163569

[32] Aydin Y A and Aksoy N D 2009 Chem. Eng. J. 151188

[33] Weber T W and Chakkravorti R K 1974 AICHE J. 20228

[34] Greenwood N N and Earnshaw A 1988 Chemistry of elements (New York: Pergamon; Springer Verlag Press) p 626 
[35] Jung C, Heo J, Han J, Her N, Lee S J, Oh J et al 2013 Separ. Purif. Technol. 10663

[36] Luo C, Tian Z, Yang B, Zhang L and Yan S 2013 Chem. Eng. J. 234256

[37] Niyogi S, Abraham E T and Ramakrishana S V 1998 J. Sci. Indus. Res. 57809
[38] Gogate P R and Pandit A B 2004 Adv. Environ. Res. 8553

[39] Singanan M and Singanan V 2007 Electro. J. Environ. Agri. Food Chem. 62557

[40] Bai A, Sudha R and Emilia A 2003 Biores. Technol. 8717

[41] Redlich O and Peterson D L 1959 J. Phys. Chem. 631024

[42] Huang R, Yang B and Liu Q 2013 Appl. Polym. Sci. 129908 